\title{
IN VITRO AND IN VIVO EVALUATION OF LYOPHILIZED BOVINE BONE BIOCOMPATIBILITY
}

\author{
Carlos Roberto Galia, ${ }^{\mathrm{I}}$ Carlos Alberto Macedo, ${ }^{\mathrm{I}}$ Ricardo Rosito, ${ }^{\mathrm{I}}$ Tielle Muller de \\ Mello, ${ }^{\mathrm{II}}$ Lourdes Maria Araújo Quaresma Camargo, ${ }^{\mathrm{III}}$ Luis Fernando Moreira ${ }^{\mathrm{I}}$
}

doi: 10.1590/S1807-59322008000600016

Galia CR, Macedo CA, Rosito R, Mello TM, Camargo LMAQ, Moreira LF. In vitro and in vivo evaluation of lyophilized bovine bone biocompatibility. Clinics. 2008;63:801-6.

INTRODUCTION: The use of bone grafts in orthopedic, maxillofacial and dental surgery has been growing. Nevertheless, both fresh autografts and frozen allografts have limitations, and therefore, alternative synthetic or natural biomaterials, such as processed and lyophilized bovine bone graft have been developed.

OBJECTIVE: To evaluate in vitro and in vivo biocompatibility of lyophilized bovine bone manufactured in a semi-industrial scale, according to a modifical protocol developed by the authors.

METHODS: Samples of bovine cancellous bone were processed according to a protocol developed by Kakiuchi et al., and modified to process samples of bovine cancellous bone. The following trials were performed: in vitro cytotoxicity, in vivo acute systemic toxicity, in vivo oral irritation potential, in vitro pyrogenic reaction, and bioburden.

RESULTS: The in vitro evaluation of lyophilized bovine cancellous bone revealed an absence of cytotoxicity in $100 \%$ of the samples. Regarding in vivo evaluation of acute systemic toxicity, neither macroscopic abnormalities nor deaths were noted in the animals. Pyrogenicity was not greater than $0.125 \mathrm{UE} / \mathrm{ml}$ in any of the samples. The bioburden revealed negative results for microbial growth before sterilization. Regarding the oral irritation potential, in vivo evaluation at 24 and 72 hours showed that the animals had no edema or erythema on the oral mucosa.

CONCLUSION: The protocol changes established by the authors to prepare lyophilized bovine cancellous bone at a semi-industrial scale is reproducible and yielded a product with excellent biocompatibility.

KEYWORDS: Surgery; Materials testing; Toxicity tests; Freeze drying; Bone transplantation.

\section{INTRODUCTION}

The use of bone grafts in orthopedic, maxillofacial and dental surgeries has been growing. ${ }^{1}$ Fresh autografts remain the standard option because of their structural properties, absence of immune response, and osteoinductive, osteoconductive and osteogenic properties. However,

\footnotetext{
I School of Medicine, Universidade Federal do Rio Grande do Sul (UFRGS) - Porto Alegre/RS, Brazil.

II School of Biological Sciences, Pontifícia Universidade Católica do Rio Grande do Sul (PUCRS) - Porto Alegre/RS, Brazil.

III Tissue Bank, Hospital de Clínicas de Porto Alegre (HCPA) - Porto Alegre/ RS, Brazil.

Email: cgalia@hcpa.ufrgs.br

Tel.: 55512101.8628 / 9986.4469

Received for publication on July 18, 2008

Accepted for publication on August 5, 2008
}

disadvantages such as longer surgical times, low availability and morbidity have limited their use.,3

Frozen allografts have also been widely used and are considered an excellent alternative since there is virtually no site morbidity, but availability is limited; and, although rare, transmission of infectious and tumoral diseases may be associated. ${ }^{4-6}$

Therefore, alternative synthetic or natural biomaterials such as processed and lyophilized bovine bone grafts, as well as different bone processing and storage methods, have been developed and extensively studied. Bovine grafts have almost unlimited availability and great physical and chemical similarity to human bone. One of the disadvantages of bovine bone is the fact that it is a xenograft and, therefore, may trigger unwanted immunological and inflammatory host reactions host. Many efforts to develop an optimal protocol 
have been attempted including physical and chemical processing methods to minimize risks and to substantially decrease antigenicity, thus rendering bovine bone an acceptable alternative to autografts and allografts..$^{7-10}$

One of the most important phases in the development and biological validation of biodegradable materials is the performance of rigorous clinical and experimental in vitro and in vivo trials to determine and confirm biocompatibility and bioactivity. ${ }^{11-13}$

Data obtained in these studies may determine whether the material meets the biocompatibility standards for implantable medical products. Methods and standards to evaluate the biocompatibility of these products are described in the ISO 10993-11 series of international norms. ${ }^{14}$ The ISO norms have exceeded several attempts and international agreements aimed at standardizing the evaluation of medical product safety and have been incorporated in several studies. ${ }^{15}$

This study evaluated the biocompatibility of lyophilized bovine bone manufactured in a semi-industrial scale according to a novel preparation process developed by the authors. The following assessments were performed: in vitro cytotoxicity, in vivo acute systemic toxicity, in vivo oral irritation potential, in vitro pyrogenic reaction, and bioburden.

\section{MATERIALS AND METHODS}

\section{Samples}

Samples of bovine cancellous bone were processed according to a protocol developed at the Osaka University, Japan $^{16}$ with modifications to decrease fat content, to improve purification of the bone graft, and by use of chemical reagents capable of inactivating viruses ${ }^{17,18}$ and possibly prions. ${ }^{19,20}$ The modifications were as follows: (1) the time of graft exposure to chloroform and methanol was increased to approximately 25 days; (2) grafts were washed using an ultrasonic washer to optimize removal of organic residues, (3) immersed in hydrogen peroxide for $1 \mathrm{~h}(10,20$ and 30 volumes), and (4) plunged into sodium hypochlorite. Finally, (5) the bones were cut in different shapes and granulations, were lyophilized, packed and sterilized by gamma radiation.

The $30 \times 20 \times 10 \mathrm{~mm}$ graft samples were sent to the laboratory in double packages made of surgical paper and PVC film, containing a chemical radiation dosimeter, and only those samples selected to determine bioburden were sent to the laboratory before sterilization.

The tests described below were performed by outside independent laboratories that also perform biologic, microbiologic physical and chemical tests for the pharmaceutical, medical and hospital industries. These laboratories have nationally and internationally Good Laboratory Practices Accreditation and are approved by the Brazilian Network Laboratories for Health Analysis (Rede Brasileira de Laboratórios Analíticos em Saúde - REBLAS) to perform biologic and microbiologic tests. The tests were performed at three distinct different laboratories in São Paulo, SP Brazil.

\section{In vitro evaluation of cytotoxicity}

Cell culture: The NCTC Clone 929 lines of mouse fibroblast cells (ATCC CCL-1) were used. Cells were grown in minimal Eagle medium supplemented with $10 \%$ fetal bovine serum (MEM $+10 \%$ FBS). Cells were maintained at $36^{\circ} \mathrm{C}$ and dispersed using $0.2 \%$ trypsin and $0.02 \%$ EDTA (TE). After dispersion, cells were resuspended in MEM and placed in bottles as control cells and on Petry dishes for agar diffusion. ${ }^{21,22}$

Three test samples containing processed and lyophilized bovine cancellous bones in a solid, liquid or powder state underwent extraction, which was performed with saline or cottonseed oil at $37^{\circ} \mathrm{C}$ for $24 \mathrm{~h}$ and at $50^{\circ} \mathrm{C}$ for $72 \mathrm{~h}$.

A negative control group was composed of nontoxic filter paper disks $0.5 \mathrm{~cm}$ in diameter, and a positive control group was composed of toxic latex fragments measuring 0.5 x $0.5 \mathrm{~cm}$.

Agar diffusion: The NCTC L929 cells lines were grown as described above, seeded on Petri dishes at a concentration of about $3 \times 10^{5}$ cells $/ \mathrm{ml}$, and were incubated for $48 \mathrm{~h}$ at $37^{\circ} \mathrm{C}$ in a $5 \% \mathrm{CO}_{2}$ humidified incubator to form a monolayer. The liquid culture medium was replaced with a solid medium composed of equal parts of double-concentrated MEM medium and BBL agar (BD) containing $0.1 \%$ neutral red vital stain (USP XXIII/2005, ISO 10993-5). The solid samples were placed directly on the solid agar medium; the liquid samples were poured on nontoxic filter paper disks and placed on the medium; and the powder samples were placed in a cylinder fixed above the medium. The dishes were incubated again for $24 \mathrm{~h}$. The samples were evaluated macro- and microscopically, and cytotoxicity was confirmed when a halo was found under or around the test sample. Halo diameters were measured, in quadruplicate and a mean value was calculated and subtracted from the diameter of the nontoxic filter paper disks used to soak the samples to obtain the zone index (ZI), which is the unstained area by the vital stain. ZIs were scored from zero to four, where zero corresponds to no halo under or around the sample, and four corresponds to a halo greater than $1.0 \mathrm{~cm}$ around the sample. Cytotoxicity values were correlated to the ZI scores of each sample, varying from absent to severe cytotoxicity. ${ }^{21,23}$ 


\section{In vivo evaluation of acute systemic toxicity}

Animals: Twenty Albino Swiss male mice with a mean weight of $20 \mathrm{~g}$ divided into two groups were used for this study.

Tests: Different media and administration routes were used for each group of ten animals. In group 1, cotton seed oil was used as the medium for the intraperitoneal injection, while in group 2, non-pyrogenic sterile saline was used for intravenous injection. On each group, five animals were considered for tests or as controls. The intraperitoneal substrate for injection that were produced in an autoclave at $121^{\circ} \mathrm{C}$ for $1 \mathrm{~h}$.

In group 1, animals were intraperitoneally injected with $1.0 \mathrm{ml} / 20 \mathrm{~g}$ body weight of sterile cotton seed oil (batch no. 103K0064). Animals in the test subgroup received $1.0 \mathrm{~g}$ of bone sample per $20.0 \mathrm{ml}$ of cotton seed oil, and the control subgroup received only sterile cotton seed oil.

In group 2, animals were intravenous injected with $1.0 \mathrm{ml} / 20 \mathrm{~g}$ body weight of non-pyrogenic sterile saline. Animals in the test subgroup received $1.0 \mathrm{~g}$ of bone sample per $20.0 \mathrm{ml}$ of non-pyrogenic sterile saline solution (batch no. 060406Q1001), while the control subgroup only received non-pyrogenic sterile saline.

All animals were treated with disposable sterile syringes and needles, and were controlled for body weight, macroscopic changes, and number of deaths at 4, 24, 48 and $72 \mathrm{~h}$. The animals were kept in special cages in the laboratory facility and received mouse chow and water ad libitum, specific care, such as light-dark cycles, room temperature and noise control, by the veterinarians and biologists involved in the study. ${ }^{24}$

\section{In vivo evaluation of the oral irritation potential}

Animals: Twelve Male Cavia porcellus (Guinea pigs) (mean weight $=570 \mathrm{~g}$ ) were used. The animals were kept at 18 to $21^{\circ} \mathrm{C}$ at $64 \%$ humidity and 12 -hour light-dark cycles (12LD).

Tests: Two groups of six animals were divided in a test group and a show-treated (controls) group. The extract was prepared at a concentration of $0.2 \mathrm{~g}$ of bone sample per $\mathrm{ml}$ of deionized water and incubated at $121^{\circ} \mathrm{C}$ for $1 \mathrm{~h}$.

The extract was applied for 10 consecutive days on the oral mucosa of the six animals in the test group. Before application, the mucosa of each animal was daily examined macroscopically by a distinct technician than that one who had applied the extract, and changes if any were recorded. Only deionized water was applied to the oral mucosa of, all animals in the control group.

For the final classification of the extract, the criterion of the Brazilian Institute of Health Quality Control (Instituto
Nacional de Controle de Qualidade em Saúde - INCQS) was used. The arithmetic means of readings for edema and erythema were calculated at 24 and $72 \mathrm{~h}$. Thus, an index was calculated by the average of four means - two readings per day in two reading days.

\section{In vitro evaluation of pyrogenicity}

The Limulus Amebocyte Lysate (LAL) assay (batch no. FL 0842 ) of $0.125 \mathrm{UE} / \mathrm{ml}$ (unit of endotoxin per $\mathrm{ml}$ ) sensitivity was used for qualitative evaluation of endotoxins produced by the bone samples if any. A mixture of $0.1 \mathrm{ml}$ LAL and $0.1 \mathrm{ml}$ of the extract was prepared in a test tube.

The mixture was immediately incubated for $1 \mathrm{~h}$ at a controlled temperature of $37^{\circ} \mathrm{C}$. After that, the tubes were removed and checked for a fixed gel formation that did not slide when the tube was positioned upside down. This method was based on the chain reaction between the bacterial endotoxin and a protein component of LAL, which produces an easily identifiable opaque gel. The formation of a gel in the bottom of the tube indicated a positive response for endotoxin production by the sample, in an amount equal to or greater than A lysate of $0.125 \mathrm{UE} / \mathrm{ml}$ sensitivity value as specified on the reagent label. Since was considered negative $(<0.125 \mathrm{UE} / \mathrm{ml})$ no gel formation can be observed.

\section{Determination of microbial load (bioburden)}

To determine the microbial load before sterilization, the extract were labeled, placed in double blister packs and sent for analyzes to the three distinct laboratories involved in the study. For each of the three samples, a pool of granulate samples was prepared and diluted in $0.9 \%$ sterile saline at a 1:10 ratio. Serial dilutions were plated in tryptic soy agar (TSA) and incubated at $35^{\circ} \mathrm{C}$ for $24-48 \mathrm{~h}$ to read the total aerobic mesophiles. Serial dilutions were also plated in Sabouraud agar and incubated at $25^{\circ} \mathrm{C}$ for 5 days to read the total filamentous fungi. At those time points, colonies of 30300 colony forming units (CFU/g) were counted.

\section{RESULTS}

\section{In vitro evaluation of cytotoxicity potential}

In vitro evaluation of lyophilized bovine cancellous bone showed no cytotoxicity potential in $100 \%$ of the samples. There were no statistically significant differences between control groups (nontoxic filter paper disks $0.5 \mathrm{~cm}$ in diameter) and test group containing sample of lyophilized bovine cancellous bone. ZI scores were zero; that is, there were no stained areas under or around the samples. There 
was, however, a statistically significant difference between these groups and the positive control group, which had a ZI of 4, indicating a stained area greater than $1.0 \mathrm{~cm}$ around the sample (Table 1).

Table 1 - Macroscopic and microscopic zone index of test and control groups

\begin{tabular}{lcccc}
\hline & \multicolumn{4}{c}{ Petry dish readings } \\
\cline { 2 - 5 } & No. 1 & No. 2 & No. 3 & No. 4 \\
\hline Samples & ZI & ZI & ZI & ZI \\
Test (bovine bone) & 0 & 0 & 0 & 0 \\
Negative control & 0 & 0 & 0 & 0 \\
Positive control & 4 & 4 & 4 & 4 \\
\hline
\end{tabular}

\section{In vivo evaluation of acute systemic toxicity}

During the study, all mice in the test subgroup of group 1 had a mean weight gain of $0.5 \mathrm{~g}$ (from $20.7 \mathrm{~g}$ to $21.2 \mathrm{~g}$ ), and the animals in the control subgroup had a mean weight gain of $0.6 \mathrm{~g}$ (from $21.9 \mathrm{~g}$ to $22.4 \mathrm{~g}$ ); In group 2 of intravenous injections, animals in the test subgroup had a mean weight gain of $0.5 \mathrm{~g}$ (from $20.1 \mathrm{~g}$ to $20.6 \mathrm{~g}$ ) and controls had a mean weight gain of $0.6 \mathrm{~g}$ (from $22.3 \mathrm{~g}$ to $22.9 \mathrm{~g}$ ); these differences were also not statistically significant.

No macroscopic abnormalities were noted and there were no deaths in either of the subgroups (Table 2 and 3).

\section{In vivo evaluation of the oral irritation potential}

No significant changes in weight or general conditions were found in the negative control group or in the test group. Observations on the test and control groups at 24 and $72 \mathrm{~h}$

Table 2 - Mean initial and final weight in all animals

\begin{tabular}{lcc}
\hline Readings & Initial weight $(\mathrm{g})$ & Final weight $(\mathrm{g})$ \\
\hline Test group 1 (extract) & 20.7 & 21.2 \\
Control group 1 & 21.8 & 22.4 \\
(cotton sees oil) & & \\
Test group 2 (extract) & 20.1 & 20.6 \\
$\begin{array}{l}\text { Control group 2 } \\
\text { (saline solution) }\end{array}$ & 22.3 & 22.9 \\
\hline
\end{tabular}

showed that none of the Guinea pigs had edema or erythema on the oral mucosa.

\section{Evaluation of pyrogenicity}

All samples showed a negative pyrogenic result, since lysates were $<0.125 \mathrm{UE} / \mathrm{ml}$ and no gel formation occurred.

\section{Determination of microbial load (bioburden)}

The tests to determine product bioburden showed negative results for microbial growth before sterilization. The physical and chemical processing procedure applied to the bovine cancellous bone samples resulted in a product free of aerobic mesophilic bacteria, filamentous fungi and yeast.

\section{DISCUSSION}

The low availability and inherent risks associated with the use of bone autografts and allografts have led several researchers to study and develop alternative bone substitutes, such as calcium phosphate ceramics and lyophilized animal bone grafts. Several products have been developed, and processing and production methods have improved. ${ }^{9,25}$

In this study, we used lyophilized bovine bone grafts produced by modifying a protocol originally developed by Kakiuchi et al. ${ }^{16}$ at Osaka University, Japan to minimize mechanical, physical and chemical changes, to reduce fat content, and to increase purity of the bone graft. Therefore, for analytical purposes, it is very similar to deep-frozen, unprocessed bone allografts. ${ }^{9}$ Private companies participated in improving this technique because of the large scale required for industrial production.

Evaluating the biologic safety of a medical product is part of the process of risk management and analysis. Tests must be selected according to the type of contact that the product will have with the host (i.e., superficial, external or implantable), the nature of the place in which the product will be applied, and the length of contact between the product and host. ${ }^{11-13,26}$

Quantitative or qualitative biocompatibility tests are quick and have been simplified, turning into systematic, detailed and safe procedures. Analyzis of material properties is currently a common practice in the industrial when both,

Table 3 - Mean weight and number of deaths in group 2

\begin{tabular}{|c|c|c|c|c|c|c|c|}
\hline Readings & Initial weight (g) & Final weight (g) & $4 \mathrm{~h}$ & $24 \mathrm{~h}$ & $48 \mathrm{~h}$ & $72 \mathrm{~h}$ & No. deaths \\
\hline Test group (extract) & 20.1 & 20.6 & Zero & Zero & Zero & Zero & $0 / 5$ \\
\hline Control group (saline solution) & 22.3 & 22.9 & Zero & Zero & Zero & Zero & $0 / 5$ \\
\hline
\end{tabular}


adapting new production methods and analyzis of final products are considered. In some cases, these tests may preclude the performance of other biologic tests. ${ }^{15}$

Systemic toxicity studies evaluate potential adverse effects of medical products on other tissues and organs other than those caused at the initial contact. These tests evaluate the effects that any substance released by the implantable product may have on the host general health or organs, such as liver, heart, kidneys or brain. ${ }^{14}$

The ISO 10993-11 norm, ${ }^{14}$ which is pliable in terms of study designs to investigate such effects, has established systematic international testing norms that have increased the safety of biomedical products. Study protocols should be based on classic toxicological evaluations of drugs and other chemical substances. However these protocols should be modified to evaluate solid components on medical products. ${ }^{27}$ The product tested in our study did not show any systemic reaction, confirming its biocompatibility, an essential requirement for its use.

The in vitro cytotoxicity test is a fast, standardized, sensitive and low-cost test to determine whether a material contains significant amounts of extractable substances that may harm the host. The results of our in vitro cytotoxicity tests, which prevent the use of experimental animals, showed a good correlation with those reported on in vivo studies of short-term implants. ${ }^{27}$ The results of cytotoxicity tests showed that the end product did not have any toxic potential that might cause reactions in surromding tissues after implantation i.e., no toxic substance was released by the processed bone, as well as no chemical residue was found at significant levels that might cause tissue damage.

The oral mucosa irritation test focused on whether the product would cause irritation when in contact with the oral mucosa of Guinea pigs, a useful model, to determine changes and lesions that may affect the stratified epithelium. ${ }^{28}$ The results of our study indicated that the bone product under analysis showed no mucosa harm further supporting itsbiosafety.

Contamination with bacterial endotoxins (pyrogenic substrates) is often associated with fever, but other substances released by distinct materials may also cause this side effect.

An evaluation of the pyrogenic potential of a material is typically included in biocompatibility studies. Pyrogenic reactions due to contamination by endotoxins are closely associated with the manufacturing processes, and assessment of contamination is part of the routine measures of production control of any material. ${ }^{29}$ This study showed that our end product was pyrogen-free, particularly free of bacterial endotoxins or other substances that might cause fever when released.

The efficiency of a product sterilization depends on the type and number of microorganisms (bioburden) found in that product. Therefore, knowing the microbial load before sterilization helps to determine parameters for sterilization and to plan a more adequate and shorter, less intense sterilization than when the process is based on an arbitrary number of organisms. Implantable products belong to the group of medical health products that require control of the microbial load acquired during manufacture and handling. ${ }^{30}$ A simple method to determine bioburden should be used not only for routine examination of end-products before sterilization but also to provide manufacturers on important data for designing and controlling production processes, particularly considering major sources of contamination. ${ }^{31}$

Our tests to determine product bioburden showed that our product had a very low microbial load and this information was consided to define and validate the sterilization process to be used in this product. Additionally, the risks associated with the original characteristics of the product and its microbial load, the selection of an appropriate sterilization method should also consider the production process, the product itself and purpose. ${ }^{32}$

After evaluating the results of bioburden tests, a minimum irradiation dose was defined for sterilization. and by using a pharmaceutical sterilization test, the dose of $20 \mathrm{kGy}$ was then validated considering a safety margin to irradiate the product. ${ }^{33}$ Of the microorganisms already associated with human bone grafts, all, but anaerobic spores, are highly sensitive to gamma radiation. Several reports showed that high radiation doses (greater than $25 \mathrm{kGy}$ ) affect the mechanical properties of bone. ${ }^{34}$ Therefore, the use of lower doses, combined with cleaning and inactivation methods or the use of preserving radiation, may safely sterilize bone assuring maintenance of functional, chemical and structural properties. ${ }^{35,36}$

\section{CONCLUSIONS}

In vivo and in vitro tests showed that lyophilized bovine cancellous bone prepared at a semi-industrial scale according to a protocol developed by the authors is a reproducible product with excellent biocompatibility. 


\section{REFERENCES}

1. Finkemeier CG. Bone-grafting and bone-graft substitutes. J Bone Joint Surg Am. 2002;84-A:454-64

2. Laurencin CT. Bone Graft Substitute Materials. Bridgeport: ASTM International; 2003

3. Seiler JG 3rd, Johnson J. Iliac crest autogenous bone grafting: donor site complications. J South Orthop Assoc. 2000;9:91-7.

4. Lind M, Krarup N, Mikkelsen S, Horlyck E. Exchange impaction allografting for femoral revision hip arthroplasty: results in 87 cases after 3.6 years' follow-up. J Arthroplasty. 2002;17:158-64.

5. Palmer SH, Gibbons CL, Athanasou NA. The pathology of bone allograft. J Bone Joint Surg Br. 1999;81:333-5.

6. Sugihara S, van Ginkel AD, Jiya TU, van Royen BJ, van Diest PJ, Wuisman PI. Histopathology of retrieved allografts of the femoral head. J Bone Joint Surg Br. 1999;81:336-41.

7. Taga EM. Biomateriais para uso em clínica medico-odontológica. Rev Bras Cir Implant. 1996;3:59-69.

8. Morax S, Hurbli T, Smida R. [Bovine heterologous bone graft in orbital surgery]. Ann Chir Plast Esthet. 1993;38:445-50.

9. Galia CR. Enxertos ósseos liofilizados impactados humano e bovino em revisão de artroplastia total de quadril [dissertation]. Porto Alegre (RS): Universidade Federal do Rio Grande do Sul; 2004.

10. Meyer S, Floerkemeier T, Windhagen H. Histological osseointegration of Tutobone $((\mathrm{R}))$ : first results in human. Arch Orthop Trauma Surg. 2008;128:539-44.

11. Williams D. Revisiting the definition of biocompatibility. Med Device Technol. 2003;14:10-3.

12. Nuss KM, Auer JA, Boos A, von Rechenberg B. An animal model in sheep for biocompatibility testing of biomaterials in cancellous bones. BMC Musculoskelet Disord. 2006;7:67.

13. Pearce AI, Richards RG, Milz S, Schneider E, Pearce SG. Animal models for implant biomaterial research in bone: a review. Eur Cell Mater. 2007;13:1-10.

14. ISO - International Organization for Standardization. ISO 10993-11: Biological evaluation of medical devices. Designing Subchronic and Chronic Systemic Toxicity Tests. http://marketplace.aami.org/eseries/ scriptcontent/docs/Preview\%20Files\%5C10993110610preview.pdf. Access: 03/04/2008.

15. Wallin RF. Biocompatibility: A quarter century of progress. MDDI 2004:146-51.

16. Kakiuchi M, Ono K, Nishimura A, Shiokawa H. Preparation of bank bone using defatting, freeze-drying and sterilisation with ethylene oxide gas. Part 1. Experimental evaluation of its efficacy and safety. Int Orthop. 1996;20:142-6

17. Mbithi JN, Springthorpe VS, Sattar SA. Chemical disinfection of hepatitis A virus on environmental surfaces. Appl Environ Microbiol. 1990;56:3601-4.

18. Aranda-Anzaldo A, Viza D, Busnel RG. Chemical inactivation of human immunodeficiency virus in vitro. J Virol Methods. 1992;37:71-81.
19. Taylor D. Inactivation of the BSE agent. C R Biol. 2002;325:75-6.

20. Chappard D, Fressonnet C, Genty C, Baslé MF, Rebel A. Fat in bone xenografts: importance of the purification procedures on cleanliness, wettability and biocompatibility. Biomaterials. 1993;14:507-12.

21. ISO - International Organization for Standardization. ISO 10993-5: Biological evaluation of medical devices, Part 5: tests for in vitro cytotoxicity. http://marketplace.aami.org/eseries/scriptcontent/docs/ Preview\%20Files/10993-5preview.pdf. Access: 03/10/2008.

22. U.S. Pharmacopeia XXVIII. The United States Pharmacopoeia. The National Formulary. 28th ed. Rockville: United States Pharmacopeial Convention; 2005.

23. U.S. Pharmacopeia XXIII. The United States Pharmacopoeia. The National Formulary. 28th ed. Rockville: United States Pharmacopeial Convention; 2005.

24. U.S. Pharmacopeia XXVIII/NF. The United States Pharmacopoeia. The National Formulary. 28th ed. Rockville: United States Pharmacopeial Convention; 2005

25. Giovani AM, Croci AT, Oliveira CR, Filippi RZ, Santos LA, Maragni GG, et al. Comparative study of cryopreserved bone tissue and tissue preserved in a $98 \%$ glycerol solution. Clinics. 2006;61:565-70

26. Wenz B, Oesch B, Horst M. Analysis of the risk of transmitting bovine spongiform encephalopathy through bone grafts derived from bovine bone. 2001;22:1599-606.

27. Sendelbach LE, Wallin RF. A Practical Guide to ISO 10993-11: Designing Subchronic and Chronic Systemic Toxicity Tests. MDDI. 1998;20:102-5.

28. Wallin RF, Arscott EF. A Practical Guide to ISO 10993-5: Cytotoxicity. MDDI. 1998;20:96-8.

29. Eveson JW. Animal models of intra-oral chemical carcinogenesis: a review. J Oral Pathol. 1981;10:129-46.

30. Anand VP. Biocompatibility Safety Assessment of Medical Devices: FDA/ISO and Japanese Guidelines. MDDI. 2000;22:206-9.

31. Lambert RJ. A model for the thermal inactivation of micro-organisms. J Appl Microbiol. 2003;95:500-7.

32. Bryans T, Alexander K. Using recovery tests to assess bioburden procedures. MDDI. 2002;10:73-9.

33. American National Standards Institute - ANSI. ANSI/AAMI/ISO 11137/2006 Sterilization of Healthcare Products: Requirements for Validation and Routine Control - Radiation Sterilization. http://www. berkshire.com/ansi.shtml.

34. Fideler BM, Vangsness CT Jr, Lu B, Orlando C, Moore T. Gamma irradiation: effects on biomechanical properties of human bone-patellar tendon-bone allografts. Am J Sports Med. 1995;23:643-6.

35. Moreau MF, Gallois Y, Baslé MF, Chappard D. Gamma irradiation of human bone allografts alters medullary lipids and releases toxic compounds for osteoblast-like cells. 2000;21:369-76.

36. Nguyen H, Morgan DA, Forwood MR. Sterilization of allograft bone: effects of gamma irradiation on allograft biology and biomechanics. Cell Tissue Bank. 2007;8:93-105. 